\title{
Computational and Analytic Perspectives on the Drift Paradox*
}

\author{
V. B. Pasour ${ }^{\dagger}$ and S. P. Ellner
}

Abstract. The fact that many small aquatic and marine organisms manage to persist in their native environments in the presence of constant advection into unfavorable habitat is known as the "drift paradox." Although advection may determine large scale biological patterns, individual behavior such as predation or vertical/horizontal migration can dominate at smaller scales. Using both computational and analytical methods to model flow in an idealized channel, we explore the extent to which biological processes can counteract physical drivers. In particular, we investigate how different zooplankton migration behaviors affect biological retention time under a variety of flow regimes and whether a combination of physical/biological regimes exists that can resolve the drift paradox, i.e., allow the zooplankton to avoid washout for time periods much greater than the hydrologic retention time. The computational model is a three-dimensional semi-implicit hydrodynamic model which is coupled with an individual-based model for zooplankton behavior, while the analytical model is a simple partial differential equation containing both advective and behavioral components. The only behavior exhibited by the zooplankton is diel vertical migration. Our studies show that the interaction of zooplankton behavior and exchange flow can significantly influence zooplankton residence time. For a channel without vegetation, the analytical methods give biological residence times that vary by at most a day from the computational results.

Key words. population dynamics, hydrodynamics, individual-based model, particle tracking, residence time, advection-diffusion equation

AMS subject classifications. 92B05, 76Z99, 35Q80

DOI. $10.1137 / 09075500 \mathrm{X}$

1. Introduction. Although physical processes were once believed to be solely responsible for nonrandom zooplankton spatial patterns, we now know that biological processes also contribute to zooplankton patchiness [40]. Over large scales, physics may dominate, or behavior may combine with physical processes to induce spatial heterogeneity. Over smaller scales, where behavioral processes such as migration and predation may control zooplankton production, individual behavior may be crucial $[10,11,50]$. In particular, many zooplankton in lakes or oceans show clear vertical migratory movement, covering significant distances daily. Migrating plankton usually move from deeper water to surface strata at dusk and then descend again at dawn, but reverse migration may reduce the risk of being eaten by nonvisual predators, who feed in the upper strata at night [43].

Motivated by the observation that zooplankton are present at high densities in moderate-

\footnotetext{
${ }^{*}$ Received by the editors April 3, 2009; accepted for publication (in revised form) by L. Fauci December 7, 2009; published electronically April 30, 2010.

http://www.siam.org/journals/siads/9-2/75500.html

${ }^{\dagger}$ Biology Department, Duke University, 125 Science Drive, Durham, NC 27708 (virginia.pasour@us.army.mil).

${ }^{\ddagger}$ Department of Ecology and Evolutionary Biology, Cornell University, E145 Corson Hall, Ithaca, NY 14853-2701 (spe2@cornell.edu).

${ }^{\S}$ Current address: Army Research Office, Durham, NC 27703.
} 
to-fast-flowing channel-like embayments (freshwater estuaries) [7, 12], we ask whether zooplankton in this type of environment can somehow avoid being flushed out of the system (as opposed to the zooplankton simply reproducing quickly enough to sustain a steady population in the embayment, a possibility we do not consider in this paper). An embayment environment, compared to the lake into which it empties, is likely warmer, more nutrient-rich, and more hospitable to the zooplankton, potentially leading to a higher growth rate, among other benefits. In this paper, we focus on understanding the extent to which biological processes can counteract physical drivers to solve the "drift paradox" (i.e., allow the zooplankton to remain in the embayment).

One possible solution to the drift paradox is the existence of an appropriate colonization cycle. Anholt [1] demonstrated that any dispersal with some sort of upstream component, not solely flight, could result in population persistence. Müller [25, 26] explained the unexpectedly high upstream density of larval aquatic insects by suggesting that when competition becomes too high upstream, some larvae drift downstream and later fly back upstream as adults. Tropical freshwater shrimps apparently undergo a similar colonization cycle (March et al. [24]). However, organisms that are continuously subject to drift or are not mobile or strong enough to overcome downstream drift cannot take advantage of such a cycle. Alternatively, Waters [45] hypothesized that organisms that drift represent excess production above and beyond the carrying capacity; however, this "production hypothesis" does not explain how the organisms that remain are able to do so. Anholt [1] argued that the production hypothesis implies that areas that suffer greater drift must experience a higher rate of population growth, or that population regulation is density dependent; using computer simulations, he concluded that density dependence is necessary for persistence. The model and results of Anholt were already criticized by Speirs and Gurney [38] and should be cited with care.

The environments to which the drift paradox refers are "predominantly unidirectional," but this description does not preclude turbulence or other variability in stream flow direction. Some recent studies have looked at the possibilities for persistence resulting from the fact that most natural water bodies do not exhibit uniform flow. Organisms can take advantage of regions of low flow (or refugia such as vegetation or rocks) (Reynolds, Carling, and Beven [32], Lancaster and Hildrew [21, 22]; Robertson, Lancaster, and Hildrew [33], Reckendorfer et al. [30], Winterbottom and coworkers [47, 48]; Rempel, Richardson, and Healey [31]; Lancaster [20]) or crawl on the benthos (Anholt [1]; Speirs and Gurney [38]; Humphries and Ruxton [15]) as a way of avoiding washout. Importantly, such refugia can serve as sources for repopulation after downstream drift depletes populations.

Speirs and Gurney [38] investigated the influence of random motion of both water (i.e., turbulence) and organisms on population persistence using advection-diffusion equations. They looked in turn at a well-mixed stream with constant advection, in which they determined the necessary balance between advection, domain size, and population growth rate for persistence, and at a weakly mixed river, in which the rate of advection is dependent on the organism's position in the water column; in the latter case, due to bottom drag, the layers nearer the benthos are moving more slowly, and a type of flow refuge exists. In Speirs and Gurney's [38] second two-dimensional model, they included a tidal oscillation and investigated the effects of near-bottom landward flow; they produced a set of "approximate inequalities" giving conditions for persistence.

Copyright (c) by SIAM. Unauthorized reproduction of this article is prohibited. 
Pachepsky et al. [28] extended the model of Speirs and Gurney to look at persistence in benthic organisms. Motivated by aquatic insects whose larvae mainly live on the benthos but occasionally jump into the flow, they divide the population into two interacting compartments, one for individuals in the benthos and one for individuals drifting in the flow, showing that compartmentalization significantly affects population persistence. Lutscher et al. [23] noted the limitations of PDE models in depicting complex asymmetrical flows and took advantage of integrodifferential equations to model the persistence of stream insects, with their probabilities of jumping into the flow as the dispersal kernel and including long-distance dispersal. They concluded that long-term persistence is always possible under high flow as long as long-distance dispersal events happen often enough and are of a sufficient magnitude.

Chen, Shaw, and Wolcott [4] attempted to isolate the effects of the tides by numerically following passive particles in a model of a small coastal-plain estuary, whose flow field was forced by oscillating tidal currents at the downstream end. Net upstream drift resulted from the combined effects of shear in the vertical direction and from tidally caused vertical motion and could partially offset net downstream transport by water flow. In addition, as the effect of the tides was greatest closest to the estuary mouth, the velocity of upstream drift increased with distance downstream, which tended to stabilize the positions of larvae in the channel. Thus, by itself, the hydrodynamics of tides could provide an important means by which larvae can be maintained in estuaries.

In this paper we investigate a situation in which flow is primarily upstream along the bottom of the channel and primarily downstream closer to the surface, and in which zooplankton periodically experience both regimes due to diel vertical migratory behavior. Such a situation might be found in a freshwater channel-like embayment emptying into a lake. While some tidal oscillation might be present, the main driver is the temperature difference between embayment and lake, which causes flow back up the channel bottom. The water flowing downstream in embayments is typically warmer than the water in the lake into which the embayment empties. Colder water has higher density than warmer water, so its hydrostatic pressure increases with depth at a higher rate than that of warmer water. If, at a certain depth, the baroclinic pressure gradient (pointing upstream) becomes strong enough to overcome the inertia of the flow downstream, it will cause upstream flow, usually at a lower depth.

Here we investigate, specifically, how zooplankton vertical migration behaviors affect biological retention time under a number of different freshwater channel flow regimes, and whether a combination of flow type and biological behavior can allow organisms to stay in the channel much longer than would a passive tracer. We address these questions by combining a three-dimensional hydrodynamic model of shallow water flow, SI3D [34, 37], with an individual-based postprocessing particle tracking module, PTRACK [34], in order to investigate zooplankton residence time under a variety of flow regimes. Next, we utilize several analytic methods, including a simple PDE taking account of flow speed in the horizontal and zooplankton location in the vertical direction. To determine the success of the analytic model, we compare our results with the numerical model results, noting the magnitude of biological residence times and the relative importance of various parameters such as background flow speed, vertical migration type, and size of zooplankton cloud.

\section{Methods.}




\subsection{Hydrodynamic model.}

2.1.1. Exchange flow. A possible mechanism for retaining zooplankton in an embayment is so-called exchange flow, which is caused by a temperature difference between the embayment and the lake, with the lake, a larger, deeper body of water, having the colder temperature in mid-to-late summer (see [29]). This type of hydrodynamic regime was implemented at the beginning of each hydrodynamic simulation through the initiation of a lock-exchange at the mouth of the embayment. A lock-exchange, or dam break, involves fluids of different densities (in this case due to temperature differences) that are separated by a vertical barrier, or lock gate. When the vertical barrier is removed, the extra weight of the denser fluid induces a larger pressure in this fluid than in the lighter fluid, causing the denser fluid to flow along the bottom of the channel, underneath the lighter fluid, which flows in the opposite direction along the top of the channel. Thus, exchange flow develops, with colder water flowing upstream along the bottom of the channel, while warmer water is flowing out the top. In the case of no background flow, Benjamin's classic gravity current result [2] gives an approximate velocity for both upstream and downstream currents of $U=\sqrt{g^{\prime} H} / 2 \approx 0.0759 \mathrm{~m} / \mathrm{s}$, where $H$ is the channel depth and $g^{\prime}=g\left(\rho_{2}-\rho_{1}\right) / \rho_{2}$ for $\rho_{1}<\rho_{2}$ is reduced gravity [2]. Background flow speeds in this study range from almost no flow, $0.0006 \mathrm{~m} / \mathrm{s}$, at which the lock-exchange flow would be expected to dominate, to relatively fast background flow of $0.0822 \mathrm{~m} / \mathrm{s}$, at which the background flow should be dominant. Simulations were run for approximately five days before particle tracking was begun to allow baroclinic adjustment of the density field and to allow the interplay between the background flow and the flow induced by the dam break to stabilize.

Figure 1 shows typical velocity and temperature profiles for high and low background flow speeds soon after the dam break. In the low flow case, exchange flow develops, while for the high flow case, the warmer water pushes the colder water out the end of the channel.

2.1.2. Channel configuration. Hydrodynamic flows were modeled using SI3D [34, 37], a semi-implicit three-dimensional hydrodynamic and transport numerical scheme for lake environments. (See [35] for a more thorough description of SI3D.) The semi-implicit nature of SI3D allows the maximization of computational efficiency and the minimization of numerical dissipation. We consider a freshwater, channel-like embayment, in an exactly rectangular geometry (1400 m long, $10 \mathrm{~m}$ wide, and $3 \mathrm{~m}$ deep), emptying into a colder lake. The embayment of interest is embedded in a much longer simulation channel (ultimately a channel length of $124,000 \mathrm{~m}$ was used); this length was chosen to avoid issues with channel flow encountering either the downstream or upstream boundary, possibly generating unphysical oscillations. Figure 2 shows a schematic of the simulated channel and the embayment's position within the channel.

The SI3D simulations used a cell size of $0.25 \mathrm{~m}$ in the vertical direction and $10 \mathrm{~m}$ in the lateral direction [29]. With this cell size, the channel required one cell in the lateral direction and 24 cells in the vertical direction. This lateral resolution is appropriate, as the dynamics of interest in the study system are primarily two-dimensional. To determine an appropriate size for computational cells in the $x$-direction, simulations were performed using cell lengths of $50 \mathrm{~m}$ and $25 \mathrm{~m}$ at both the slowest simulation flow speed and the fastest simulation flow speed. The results were compared in terms of scalar transport, with $50 \mathrm{~m}$ cells judged adequate for our purposes (see [29]). 

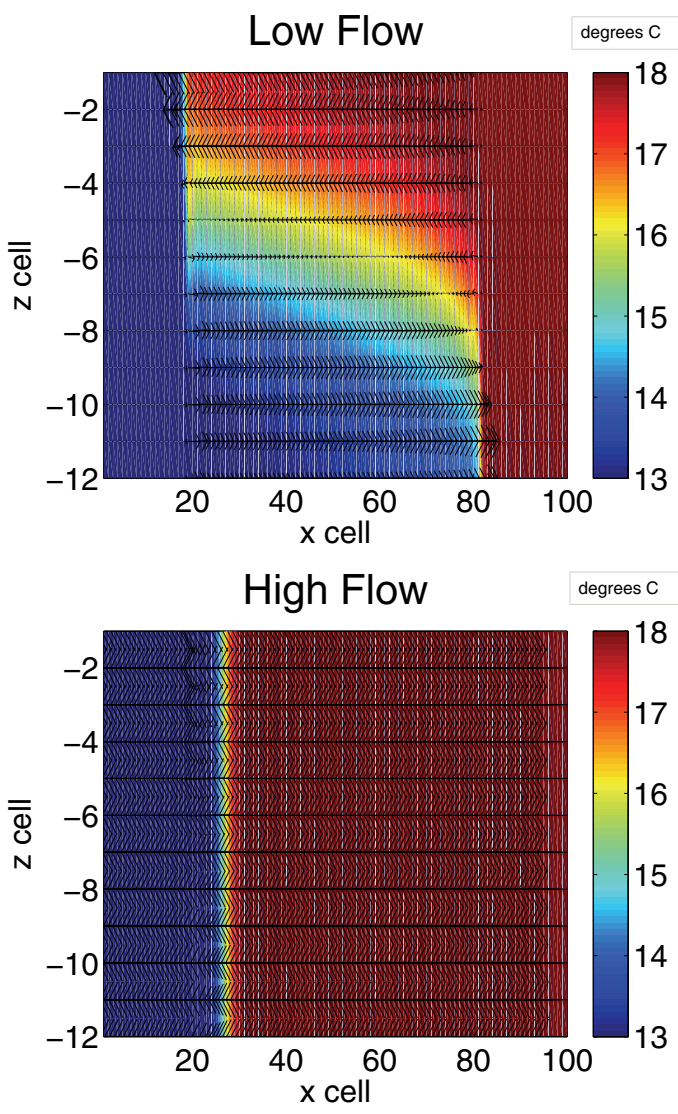

Figure 1. Figures showing, for part of the simulation region, the flow regime a day after dam break for a low flow $(0.06 \mathrm{~cm} / \mathrm{s})$ case and half a day after dam break for a high flow $(8.22 \mathrm{~cm} / \mathrm{s})$ case. Colors indicate temperature, while arrows indicate direction and relative magnitude of velocity.

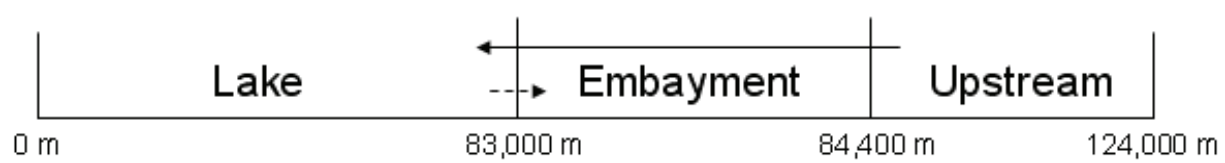

Figure 2. Side view of the computational channel, showing the relative position of the study embayment. The solid arrow denotes westward background flow, while the dashed line represents potential flow back upstream resulting from temperature differences between embayment and lake.

Turbulence can greatly affect mixing and circulation in estuaries. (At typical embayment temperatures and lowest flow speeds considered, the Reynolds number is about 1800, transitional between laminar and turbulent flow.) In SI3D, we used the Smagorinsky model [36] to determine horizontal eddy coefficients, and the Kantha and Clayson formulation [17] of the original Mellor and Yamada 2.5 second moment closure two-equation model to determine vertical eddy viscosities and diffusivities. This grid-scale turbulence model was complemented by subgrid-scale turbulence in the particle tracking algorithm by means of a random step added to the particle position in each coordinate direction at each time step.

Copyright (C) by SIAM. Unauthorized reproduction of this article is prohibited. 


\subsection{Zooplankton modeling.}

2.2.1. Particle tracking method. An add-on to the SI3D model, PTRACK, uses velocities computed in SI3D to simulate the motion of passive particles. The Lagrangian, or particle tracking, method represents particle position by the sum of successive displacements over time. Following Dunsbergen and Stelling [8], each displacement can be described by a stochastic differential:

$$
d x_{i}=a_{i}(\mathbf{x}, t) d t+\sum_{j=1}^{3} b_{i j} d W_{j}(t),
$$

where $\mathbf{x}=(x, y, z)$ is the particle position and $W_{j}(t)$ represents the Wiener process, or Brownian motion. $W_{j}(t)$ is simulated using a Gaussian number generator, with a mean of 0 and variance determined by the time step. In addition, $a_{i}$ and $b_{i j}$ must satisfy the following equations for consistency with the advection-diffusion equation describing the transport of mass $[6,8,16,18,42]$ :

$$
\begin{aligned}
& a_{i}=u_{i}+\sum_{j=1}^{3} \frac{\partial D_{i j}}{\partial x_{j}} \\
& \frac{1}{2} \sum_{k=1}^{3} b_{i k} b_{j k}=D_{i j}
\end{aligned}
$$

where $u_{i}$ is velocity, $a_{i}$ is drift, $b_{i j}$ is the magnitude of stochastic influence or noise $[8,39]$, and $D_{i j}$ is diffusion, which is assumed to be horizontally isotropic. Thus, the deterministic component of the displacement is influenced by the local velocity and the gradient of the turbulent diffusivity, and the stochastic component requires the diffusivity. These quantities, namely the velocity field and the (vertical) eddy diffusivity, are available from SI3D output and allow the use of PTRACK as a postprocessing tool. The horizontal eddy diffusivity is treated as a constant for the purposes of particle tracking and computed based on Fischer et al. [9].

PTRACK tracks particles in each of the three coordinate $(x, y, z)$ directions separately. The particles in PTRACK are assumed to be neutrally buoyant. The code includes a reflection algorithm that relocates particles in the water body when they run into physical boundaries, so that no mass is lost during particle tracking. After advecting each particle, PTRACK also includes a drift subroutine, which adds the effect of the variation of diffusion coefficients in the vertical particle displacement, as well as a random step representing particle displacement due to turbulence.

2.2.2. Adding plankton behavior. We modified PTRACK so that particles could exhibit "behavior" at appropriate times in the $z$ (vertical) direction, instead of being passive tracers. Specifically, zooplankton behavior consists of vertical migration, with zooplankton either not migrating vertically at all (the "no migration" case), migrating down in the water column at dawn and up at dusk (the "normal migration" case), or migrating up in the water column at dawn and down at dusk (the "reverse migration" case). Vertical migration takes place between

Copyright (c) by SIAM. Unauthorized reproduction of this article is prohibited. 
5:30 and 6:00 AM and between 8:30 and 9:00 PM, with plankton moving with a constant step size so that the movement is divided evenly over the half hour, until each plankter's preferred height or depth (see below), as appropriate, is reached.

The deterministic displacement of a particle requires the local flow velocity, as well as the space-varying diffusivity. As the particle positions do not often coincide exactly with the nodes used in the hydrodynamic model, a method for finding a continuous velocity field, along with continuously defined diffusion coefficients, is needed. Again following Dunsbergen and Stelling [8], we write the continuous extension of the flow field at grid cell level as

$$
u_{i}^{e x t}(\mathbf{x}, t)=\left(\frac{\partial u_{i}}{\partial x_{i}}\right)_{n u m} x_{i}+\left(\left.u_{i}\right|_{x_{i}=0}\right)_{n u m} \equiv A_{i} x_{i}+B_{i},
$$

where $A_{i}$ refers to the numerical implementation of $\partial u_{i} / \partial x_{i}$. The divergence of the continuous extension of the discrete velocity field $=0$, showing that a mass conserving hydrodynamic model implies a mass conserving advective particle tracking step. The streamline through a particular point $\mathbf{x}=\mathbf{x}_{p}$ can now be found by solving the following ODE:

$$
\begin{array}{r}
\frac{\partial x_{i}(t)}{\partial t}=u_{i}^{e x t}(\mathbf{x}, t), \\
x_{i}\left(t_{0}\right)=\left(\mathbf{x}_{p}\right)_{i} .
\end{array}
$$

This streamline can then be used to determine the time to exit one computational cell and enter another, as well as the exit point [8].

To implement plankton vertical migration, $A$ may be set to 0 and $B$ may be set to be the velocity at which the plankton need to move vertically in order to complete their migration in the time allotted. The term $x(t)=B t+x_{p}$ will then equal the distance to move vertically added to the original location in the $z$-direction. This modification is applicable only to vertical movement.

2.2.3. Rules for zooplankton movement. To prevent zooplankton from penetrating the channel bottom or water surface, each zooplankter is assigned a "preferred" height and depth, and upon its reaching this height and depth, a flag is set and further migration is prevented for that individual. Passive advection of the zooplankter is still allowed to take place; otherwise, the implication would be that the zooplankton were actively resisting the water movement. These preferred heights and depths were chosen, independently from each other for each zooplankter, from a normal distribution whose standard deviation was the same as for the initial zooplankton cloud. In addition, the possible time for migration was extended slightly past half an hour in case advection took the zooplankton closer than expected to either surface or bottom so that after a half hour of migration the preferred locations had not been reached. At the end of each vertical advective step, the new $z$-position of the zooplankter is checked, and if it is above the water surface or below the bottom of the channel, it is set back to the preferred height or depth, as appropriate. Similarly, after each migration step in the $z$-direction, the new value for $z$ is tested against the preferred height or depth as appropriate, and if it is too small or large, respectively, it is reset to the preferred value.

Copyright (c) by SIAM. Unauthorized reproduction of this article is prohibited. 
2.3. Computational parameters. We varied four parameters in our simulations: background flow rate, start time, migration type, and standard deviation of the initial zooplankton cloud size. Eighteen flow rates were used, ranging from 0.018 to $2.466 \mathrm{~m}^{3} / \mathrm{s}$, corresponding to velocities of 0.06 to $8.22 \mathrm{~cm} / \mathrm{s}$. Start times were midnight, 8:00 AM, and 4:00 PM, while migration types were either normal, reverse, or no migration. Initial zooplankton clouds were spherical, with approximate diameters of $1 / 4,1 / 2$, or $2 / 3$ of the water column height; these values were chosen to encompass the range of plankton cloud sizes observed in the field $[5,13,14,19,27,46]$. A cloud of 250 zooplankton was centered in the middle of the channel laterally and at such a depth or height, depending on the combination of the migration and start time parameters, as to just allow the cloud to remain completely in the water column, while in the longitudinal direction, the mean of the zooplankton cloud was set to be at the upstream beginning of the embayment. For each combination of flow rate and start time, SI3D generated a binary file containing the velocities at each computational grid point at each output time. This file was then utilized by PTRACK to perform particle tracking for all combinations of migration type and initial zooplankton cloud size.

\subsection{Analytic method.}

2.4.1. The model. We started with the simplest case of a two-dimensional linear stream with temporally constant (but not spatially uniform) advection and an absorbing boundary at the downstream end representing the transition to habitat unsuitable for population growth or persistence. The stream was assumed to have infinite length in the upstream direction, as downstream movement into the lake is more likely and more consequential than movement upstream in the embayment. The two dimensions in this case are the $x$ - and $z$-dimensions; in order for migrating zooplankton to experience different flows as they move up and down in the water column, the embayment must have at least two vertical layers experiencing different flow speeds. As the flow speed and temperature variability between embayment and lake are not easily represented by a simple function, we used flow field results from the hydrodynamic model as inputs to the analytic model. Once a base model was developed, various aspects of the persistence of zooplankton were explored under the same migration regimes and initial zooplankton cloud sizes as in the simulations. Our measure of persistence was "biological residence time," i.e., the mean amount of time that a zooplankter remains in the embayment before exiting for the first time.

We start with the classical advection-diffusion equation

$$
\frac{\partial n}{\partial t}+\frac{\partial(u n)}{\partial x}=\frac{\partial}{\partial x}\left(\alpha \frac{\partial n}{\partial x}\right)
$$

where $n$ is the zooplankton population density, $u$ is the velocity of the zooplankton in the $x$-direction, $\alpha$ is a diffusion coefficient, and $x$ increases from left to right. Negative values of $u$ indicate downstream flow. In this formulation, the diffusion coefficient is possibly a function of time and/or space. We assume that

(1) population density $n(t, x)$ varies with time and distance along the $x$-axis,

(2) zooplankton actively swim only in the $z$-direction,

(3) water velocity is constant in the $x$-direction but not the $z$-direction.

Copyright (c) by SIAM. Unauthorized reproduction of this article is prohibited. 
In addition, we write $u$ in the equation above as $u(z)$, where $z$ is itself a function of $t$. This change allows varying flow at different heights in the channel, while at the same time incorporating the effect of zooplankton vertical migration.

Numerical experiments were performed to evaluate the extent to which diffusion changes with time by considering a range of flows of a similar nature to what is considered in this model - i.e., primarily unidirectional flow in a channel with a lock-exchange at the downstream end and starting a zooplankton cloud at varying water column heights. We contrasted the amount of horizontal diffusion over time with height, which changes for zooplankton in a predictable way with time due to their diel vertical migration, and, in this way, determined whether the degree to which diffusion changes with time is significant. These experiments showed virtually no diffusion with time in the faster flow regimes, while in the slower flow regimes some stretching out of the zooplankton cloud was observed with time, especially for clouds starting in the center of the channel. This effect was presumably due to the larger effect of the lock-exchange flow than the background flow on the flow field, which produced a shearing effect. Thus, even in the case of very low background flows, the change in diffusion with time was demonstrated to be insignificant compared to the resulting flow in the channel. Thus, we assume that the diffusion coefficient, $\alpha$, is constant, giving

$$
\frac{\partial n}{\partial t}+u(t) \frac{\partial n}{\partial x}=\alpha \frac{\partial^{2} n}{\partial x^{2}}
$$

with initial condition $n(0, x)=A(x)$, where $n=n(t, x), t>0,-\infty<x<+\infty$. We consider in essence an infinitely long channel and make the reasonable assumptions

$$
\lim _{|x| \rightarrow+\infty} n(t, x)=\lim _{|x| \rightarrow+\infty} \frac{\partial n}{\partial x}(t, x)=0 .
$$

Equation (2.8) with the given boundary conditions physically represents advection at a rate $u(t)$ superimposed on a heat kernel spreading over time. Hence, its solution is

$$
n(t, x)=\int_{-\infty}^{+\infty} A(y) \frac{1}{2 \sqrt{\alpha \pi t}} e^{-\frac{1}{4 \alpha t}\left(\int_{0}^{t} u(\tau) d \tau-(x-y)\right)^{2}} d y
$$

which represents a diffusing cloud of zooplankton that also moves along the $x$-axis based on the specific characteristics of $u(z(t))$. We can determine how many zooplankton are in the channel as of time $t$ by integrating $n(t, x)$ over positive $x$.

Using the change of variables

$$
v=\frac{1}{2 \sqrt{\alpha t}}\left(\int_{0}^{t} u(\tau) d \tau-\left(x-x_{0}\right)\right)
$$

we obtain

$$
\int_{0}^{\infty} n(t, x) d x=\int_{-\infty}^{\infty} A(y)\left(\frac{1}{2}+\frac{1}{2} \operatorname{erf}\left(\frac{1}{2 \sqrt{\alpha t}}\left(\int_{0}^{t} u(\tau) d \tau+x_{0}\right)\right)\right) d y,
$$

where $\operatorname{erf}(x)$ is the error function. 
2.4.2. Numerical experiments. Numerical experiments were run for up to seven days to investigate biological residence time for different flow speeds, migration types, and initial zooplankton cloud standard deviations. First, one zooplankter was simulated whose starting positions in the longitudinal $(x)$ and vertical $(z)$ directions were the center of the zooplankton cloud in those directions. Thus, while the starting position in $x$ was constant throughout the simulations, the vertical positions were determined by the initial cloud standard deviation.

We used flow regimes from numerical simulations to provide $u$ values for the model. For each of the 18 values for background flow speed, taking the longitudinal values for velocity over the $1400 \mathrm{~m}$ long channel, we averaged the velocities at each vertical grid cell depth over the length of the numerical simulation. This averages out the effect of any oscillations, differing flow speeds, and directions of flow and gives a more realistic overall result than would taking a cross section at one particular location when the flow field is not homogeneous in the $x$-direction. Linear interpolation was used to calculate $u$ as a continuous function of depth.

The vertical position of migrating zooplankton was modeled by the function

$$
z(t)=1-\frac{\tanh \left[\delta \cos \left(\frac{2 \pi t}{24}\right)\right]+1}{2} .
$$

The value of $\delta$ controls the vertical migration speed. In the simulations, zooplankton migrate for approximately half an hour. Thus, for our model, we used $\delta=1000$, so that the change from top to bottom of the water column would take about the same amount of time.

We scaled $z(t)$ in (2.10) to have a maximum and minimum that are a distance equal to the radius of the zooplankton cloud from both the bottom and top, respectively, of the water column. This change was deemed desirable to keep the code relatively simple, yet take into account the fact that members of larger zooplankton clouds can find themselves in quite different flow fields than members of smaller clouds. We shifted the function appropriately in order to provide the correct number of nighttime hours, assuming a start time of midnight, before migration starts. The position function for no migration is simply a horizontal line that is a distance of the zooplankton cloud mean from the surface. The term involving $z(t)$ can be disregarded and $u$ treated as a function of $z$ instead of $t$ if the zooplankton do not migrate. Regardless of whether a zooplankter is a normal or reverse migrator, the time spent at the top of the water column is equal to the time spent at the bottom, or equivalently, night and day are of approximately equal lengths. We compare our results here with equal day/night simulations using the hydrodynamic model.

Up to this point, we have been considering the zooplankton cloud as a point whose position function follows the path of a zooplankter at the mean of the cloud. Thus, the different starting positions in the vertical direction of different zooplankton are not taken into account. Especially as flow speed decreases and the spread of the initial zooplankton cloud increases, differing vertical placements could have a significant impact on the resulting biological residence time and should be considered. Ideally, we would like to integrate biological residence time over vertical starting position. Given that the initial zooplankton cloud is normally distributed, the fraction of zooplankton remaining at time $t$ is

$$
P[T>t]=\int P\left[T>t \mid z_{0}=z\right] \Phi(z) d z,
$$

Copyright (c) by SIAM. Unauthorized reproduction of this article is prohibited. 
where $\Phi$ denotes the probability density of a normal distribution with the mean and standard deviation of the initial cloud. We computed these integrals numerically using Gaussian quadrature.

The hydrodynamical simulations allowed us to distinguish when each zooplankter crossed over between embayment and lake so that we could take the first crossing time when computing biological residence time. In contrast, for the PDE model, we cannot distinguish individuals and instead have a distribution that is moving back and forth along the channel. Within the zooplankton cloud, zooplankton should be assumed to be moving relative to each other due to turbulence and their individual migration paths. In our numerical solution of the PDE, when a fraction of the distribution first crosses the embayment-lake boundary, we determine that that fraction of zooplankton have exited the channel, thus defining their biological residence time. When a larger fraction of the distribution crosses into the lake, we assign the current time as the biological residence time for the additional fraction, without regard to whether these zooplankton have already crossed the embayment-lake threshold or not. (If that same fraction then moves back into the embayment and then out into the lake, we assume that no "new" zooplankton have exited.) Unfortunately, while this method should avoid some "double counting" of zooplankton exits, biological residence time will be overestimated.

2.4.3. Simple analytic model. To determine whether this overestimation is significant, we compared the results using the PDE to another, simpler approximation. The mean horizontal zooplankton velocity over a day remains constant throughout the simulations, due to the assumption that $u$ is homogeneous in $x$. Thus, we estimated the mean first time to exit for the zooplankton cloud as embayment length divided by the mean zooplankton horizontal velocity, found by averaging $u$ over a 24-hour period. (As in the numerical experiments discussed previously, values for horizontal water velocity were averaged over time and horizontally.) In the example above, this approximation might be expected to give a biological residence time that averages the first and second times that the new zooplankter crosses the lake-embayment boundary and thus might give results close to the true biological residence time.

\section{Computational results.}

3.1. Water flow profiles. Figure 3 shows the steady state velocity profiles for "slow" $(0.06 \mathrm{~cm} / \mathrm{s})$, "medium" $(4.38 \mathrm{~cm} / \mathrm{s})$, and "fast" $(8.22 \mathrm{~cm} / \mathrm{s})$ background flows. The axes are labeled using cell number instead of length in meters, but the area in each figure is the same as in the zooplankton trajectory figures (see Figure 4 below). The flow induced by lock-exchange under the slow and intermediate background speeds is clear here and persists throughout the area shown, with water flowing to the west in the top part of the channel and to the east in the bottom part. As the background flow speed increases, a greater proportion of the water column carries water westward and at higher speeds, while the colder water at the bottom decreases in speed. At the highest background velocity, the background flow eventually nullifies any effect of the lock-exchange, pushing water from east to west throughout the water column after an initial transient (not shown here) at approximately the background flow speed, although flow is retarded at the bottom due to drag. Note that this mean flow under the high background flow rate is greater than the expected plume speed of $7.59 \mathrm{~cm} / \mathrm{s}$ generated by a lock-exchange. The bottom right panel of Figure 3 shows the steady state

Copyright (c) by SIAM. Unauthorized reproduction of this article is prohibited. 

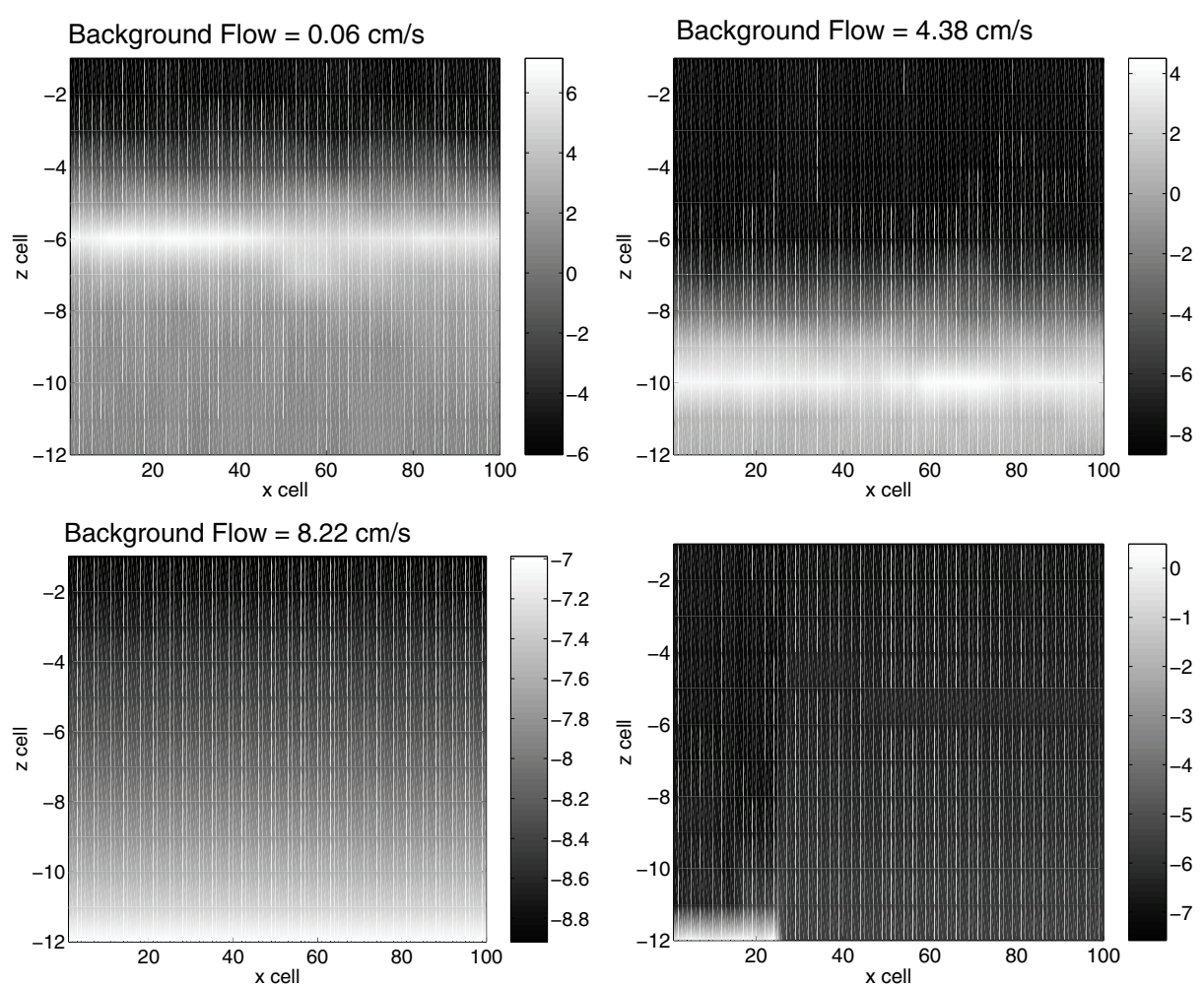

Figure 3. Steady flow field for background flow of $0.06 \mathrm{~cm} / \mathrm{s}, 4.38 \mathrm{~cm} / \mathrm{s}, 8.22 \mathrm{~cm} / \mathrm{s}$, and $6.3 \mathrm{~cm} / \mathrm{s}$. Shades of gray in the colorbar are in $\mathrm{cm} / \mathrm{s}$ and display east-west flow.

for a speed between the intermediate and high flow speeds, at which a small exchange flow occupies the western part, and unidirectional flow the eastern part, of the channel.

3.2. Zooplankton trajectories. Figure 4 shows typical plots of the beginning paths of the zooplankton clouds under the three different migration schemes. Zooplankton clouds all start with their means in the $x$-direction set at $84,400 \mathrm{~m}$, and the channel empties into the lake at $83,000 \mathrm{~m}$. As flow speed and migration type are assumed to be the most important factors affecting biological residence time, the starting time and initial zooplankton cloud standard deviation values are kept constant at midnight and the middle value for standard deviation (see section 2.2) in these figures. At midnight, zooplankton that are nonmigrators or normal migrators are located at the top of the water column, while zooplankton that are reverse migrators are located at the bottom of the water column.

When the zooplankton do not vertically migrate, the cloud basically moves straight down the channel, and in at most 15 hours, under any background flow speed, at least some of the zooplankton are gone or leaving the embayment. The background flow at $0.06 \mathrm{~cm} / \mathrm{s}$ is clearly dominated by the lock-exchange induced flow; flow is faster toward the top of the water column, although not as fast $(7.59 \mathrm{~cm} / \mathrm{s})$ as under a pure lock-exchange flow (see section 2.1 ), and slower toward the middle, which produces some shear in the zooplankton cloud. Although lock-exchange flow still exists in the intermediate flow speed case, the zooplankton cloud is 

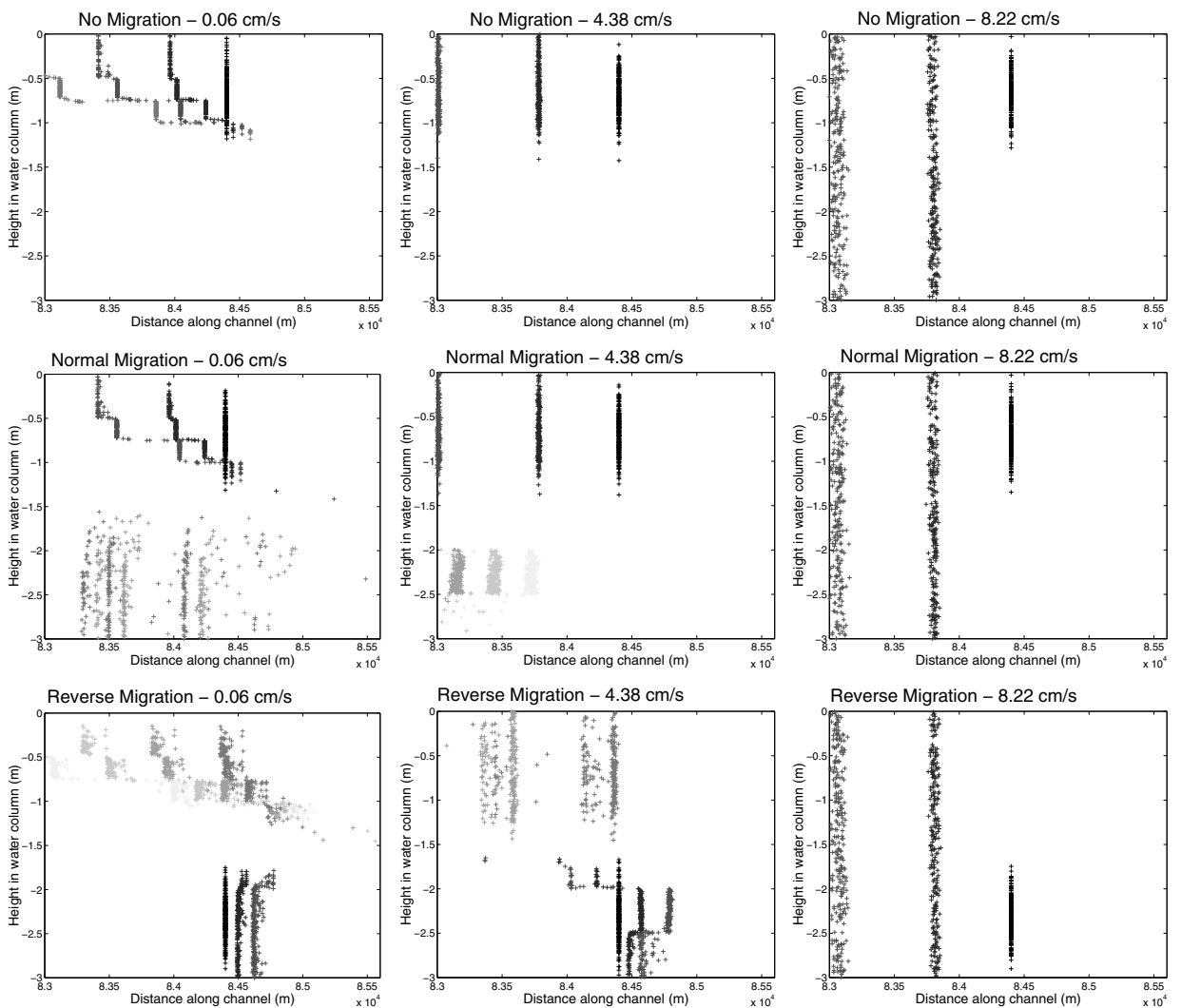

Figure 4. Zooplankton cloud movements for the three migration types and for background flow speeds of $0.06 \mathrm{~cm} / \mathrm{s}, 4.38 \mathrm{~cm} / \mathrm{s}$, and $8.22 \mathrm{~cm} / \mathrm{s}$, respectively, starting at midnight, with moderate plankton cloud standard deviation. Lighter shades of gray indicate increasing time, with sequential zooplankton clouds representing increments of 2.5 hours. Background flow east to west.

unsheared and moving at an average speed of about $7.6 \mathrm{~cm} / \mathrm{s}$, the speed expected due to the lock-exchange. In contrast, at the high flow rate, the background flow quickly pushes the lock-exchange flow out of the channel, and the entire cloud moves as a cohesive unit (as is demonstrated conclusively after 2.5 hours when the turbulent diffusivity stretches the plankton cloud throughout the water column). However, while the background flow appears to dominate the lock-exchange flow, the downstream velocity of the zooplankton cloud again appears to be approximately $7.6 \mathrm{~cm} / \mathrm{s}$, less than the background flow speed of $8.22 \mathrm{~cm} / \mathrm{s}$, demonstrating the complex interplay between background and lock-exchange flow. Only for much higher background flow speeds do we find a steady flow speed approximating the background flow speed.

When zooplankton migrate normally, the zooplankton cloud starts at the top of the water column. With a low background flow rate, the zooplankton cloud drifts downstream at first due to the exchange flow and then moves to the bottom of the water column at daybreak. At this point the zooplankton are carried upstream, but the previous migration upstream was sufficient so that the (mean) cloud at the end of the cycle is somewhat upstream from where it started; it is also much more spread out in the horizontal than it was initially due

Copyright (C) by SIAM. Unauthorized reproduction of this article is prohibited. 
primarily to the shear experienced near the water surface. As shearing will continue to take place, some zooplankton will not be able to remain in the embayment indefinitely; however, this combination of parameters allows retention of a large number of the zooplankton. Under the higher background flow regimes, the zooplankton cloud still initially moves downstream, but faster and with no shearing. The interaction of the faster background flow with the lockexchange flow clearly results in a lessened shearing effect. While for the $4.38 \mathrm{~cm} / \mathrm{s}$ background speed the zooplankton have time to migrate to the bottom of the water column and advance upstream to a certain degree before being advected out of the channel permanently, for the highest background speed the zooplankton are simply advected out of the channel.

When the zooplankton undergo reverse migration, for the low flow exchange flow regime the zooplankton cloud starts out at the bottom of the water column and moves upstream a short distance before migrating up in the water column. By the time five more hours have passed, at least half of the zooplankton are too far downstream to be able to maintain the type of semistationary cycle that occurred under normal migration; each time midnight comes around, the zooplankton do not have enough time to recover their former upstream position before they have migrated upwards and are moving downstream again. Shear carries some plankton out of the channel early, but all will be advected out of the embayment within seven days. This result is perhaps not surprising considering that reverse migrating zooplankton are at the water surface during daylight hours, and the simulation assumes more daylight than dark hours per day. In the case of a $4.38 \mathrm{~cm} / \mathrm{s}$ background speed, some of the zooplankton are carried slightly upstream from their starting location, while others are dispersed downstream, before all of the plankton migrate up in the water column and are advected out of the embayment. Under the highest background speed, as in the normal migration case, the zooplankton are simply advected out of the channel before they have a chance to undergo vertical migration. Under these higher speeds, the zooplankton cloud position ends up about the same regardless of the migration type, and all zooplankton clouds leave the embayment at about the same time, because the flow is unidirectional and varies little in the vertical.

3.3. Residence time. The mean residence time for zooplankton under every combination of flow rate, start time, migration type, and zooplankton cloud size was computed in order to determine whether these trends between migration type and biological residence time hold over the range of flow speeds investigated. Assuming conservatively that lake conditions are inhospitable or that the zooplankter might not be able to return to the embayment once in the lake, the first time that the zooplankton drifted into the lake was taken as the residence time for the zooplankter. These times for all 250 zooplankton were then averaged to get a mean residence time in days. Figure 5 gives plots for each combination of zooplankton cloud standard deviation and start time, demonstrating how each of the three migration types influences the average biological residence time across the range of flow speeds studied. As the simulation time was seven days, a mean residence time of seven days indicates that the zooplankton have avoided washout, at least on a small timescale.

Flow speed, migration type, and zooplankton cloud standard deviation all have a noticeable influence on biological residence time, although none of the conditions tested allowed all 250 zooplankton to remain in the embayment for the entire seven days. The effect of start time, on the other hand, appears to be quite small. Not migrating in general leads to the lowest residence times, although the effect is negligible at moderate-to-high flow speeds. Reverse

Copyright (c) by SIAM. Unauthorized reproduction of this article is prohibited. 

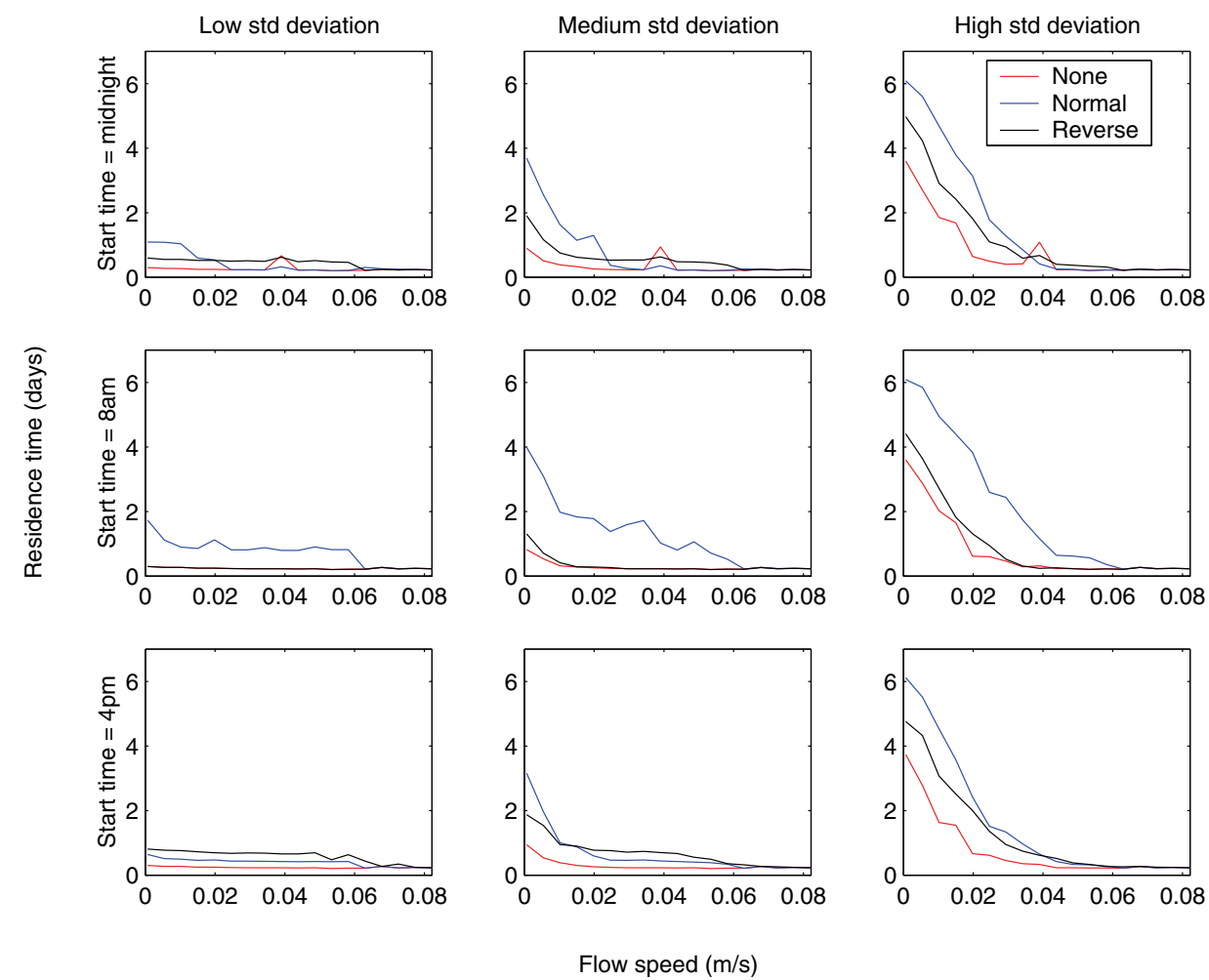

Figure 5. Mean biological residence time versus background flow speed by migration type for the nine zooplankton cloud standard deviation/start time combinations.

migrating always does somewhat better at retaining plankton in the embayment under low flow speeds than does not migrating, with the greatest effect occurring when the simulation starts at midnight or 4:00 PM. In most cases, normal migration at very low flows does the best job of keeping the zooplankton in the embayment, with residence times that are as much as two days longer than under reverse migration, but at moderate flow speeds, a drop-off in residence time occurs and normal migration loses its advantage.

As flow speed increases, mean biological residence time tends to decrease, with the most difference in residence time found at the lower flow speeds. This decrease is not strictly monotonic, due largely to the stochastic nature of the simulations. For all three standard deviation values, a spike in the biological residence time is seen at a flow speed of $3.9 \mathrm{~cm} / \mathrm{s}$. This speed is low enough to still allow exchange flow but high enough to produce a turbulent diffusivity that, together with the exchange flow, allows some particles to get caught in the upstream motion in the bottom of the channel and thus increases the mean biological residence time.

Zooplankton cloud standard deviation also plays an important role in determining biological residence time, especially at low flow speeds. Regardless of start time, all three migration types tend to increase their residence times at low flow speeds as standard deviation increases. Increasing standard deviation increases the amount of water column taken up by the cloud 

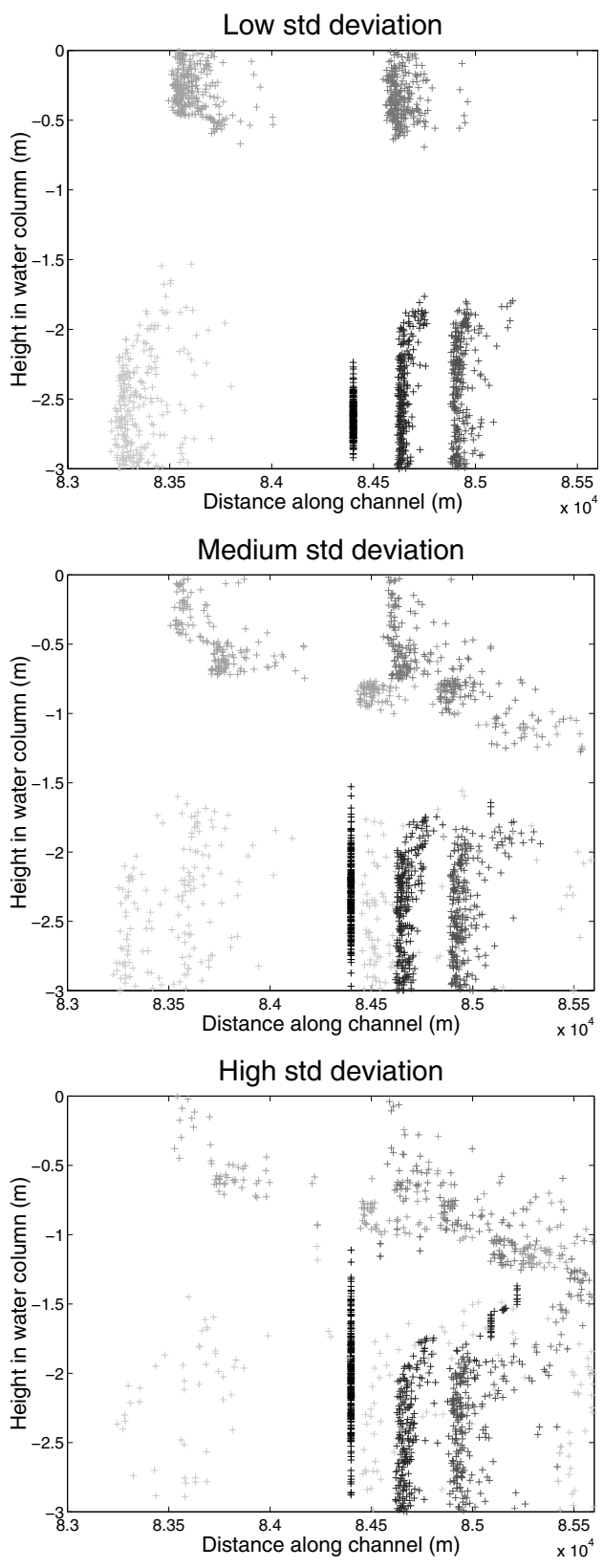

Figure 6. Particle trajectories for case of background flow of $0.06 \mathrm{~cm} / \mathrm{s}$ under low (top), medium (middle), and high (bottom) standard deviation, for normal migration and a start time of 8:00 AM. Lighter shades of gray indicate increasing time, with sequential zooplankton clouds representing increments of 5 hours. Background flow east to west.

and potentially places some zooplankton in water flowing in the opposite direction from the rest of the group, thus diversifying the movement of the plankton cloud as a whole. Figure 6 shows typical zooplankton movements for a start time of 8:00 AM under normal migration at a flow speed of $0.06 \mathrm{~cm} / \mathrm{s}$. Note that, for the sake of clarity, particle trajectories are shown 
only every 5 , instead of 2.5 , hours. As the standard deviation increases, the zooplankton become more scattered, and in particular, the shearing effect in the upper part of the water column increases, spreading the zooplankton out in the $x$-direction along the channel and even carrying some east beyond the portion of the channel pictured. This shearing effect has the greatest effect for simulations with a start time of 8:00 AM, due to the advantage of moving upstream along the bottom of the channel at the start of the simulations.

Migration times were set to be appropriate for midsummer in the Great Lakes region, resulting in a longer day than night. As other day lengths occur in other locations and times, we repeated the simulations using equi-length days and nights, with migration times of 7:30 8:30 AM and 7:30-8:30 PM. In this case, although flow speed and standard deviation have effects on biological residence similar to those in the original simulations, now reverse migration vies with normal migration to give the higher biological residence times. Not surprisingly, reverse migration produced higher residence times for start times allowing more night hours in the first 12 hours, namely, start times of midnight and 4:00 PM.

The mean residence time indicates only the fate of the zooplankton cloud on average. To account for individual organisms, the number of zooplankton left in the embayment over time was plotted for background flow speeds of $0.06 \mathrm{~cm} / \mathrm{s}, 4.38 \mathrm{~cm} / \mathrm{s}$, and $8.22 \mathrm{~cm} / \mathrm{s}$, along with all migration types, start times, and zooplankton cloud standard deviations.

In the low flow speed/midnight start time case shown in Figure 7, nonmigrators do the worst job of staying in the embayment. The most zooplankton remain in the embayment for normal migration and a large zooplankton cloud. Reverse migrators do better than nonmigrators but not nearly as well as normal migrators. Initial cloud standard deviation has a big effect on the number of zooplankton that remain in the embayment for all seven days; as standard deviation increases, more zooplankton survive until the end of the simulation. Low standard deviation zooplankton clouds leave the channel essentially all at the same time, while higher standard deviation clouds leave in spurts due to shearing caused by the exchange flow.

For an intermediate flow speed of $4.38 \mathrm{~cm} / \mathrm{s}$, with a start time of midnight and all cloud sizes, nonmigrators and normal migrators essentially leave the embayment in a clump after about six hours have passed, while reverse migrators finish leaving the embayment after about half a day. Contrary to the situation at low flow speeds, for migrators that don't leave the embayment all at once, as the zooplankton cloud standard deviation increases, the zooplankton tend to start leaving the embayment sooner and in larger clumps. Similar to the zooplankton at low flow speeds, normal migrators at the 8:00 AM start time and lower zooplankton cloud standard deviation start leaving the embayment later than reverse and nonmigrators, while reverse migrators are the last to start leaving the embayment at the midnight and 4:00 PM start times. Additionally, 4:00 PM is the only start time when nonmigrators do noticeably worse than the other migration types at remaining in the embayment.

At a background flow speed of $8.22 \mathrm{~cm} / \mathrm{s}$, neither standard deviation nor start time affected biological residence time. For all migration types, start times, and standard deviations, the zooplankton cloud leaves the embayment all at once after about six hours, because the background flow is too high for the lock-exchange to create a lasting exchange flow.

3.4. Statistical analysis. To quantify the influence of the various model inputs on biological residence time, simulations were run and biological residence time computed for all

Copyright (c) by SIAM. Unauthorized reproduction of this article is prohibited. 

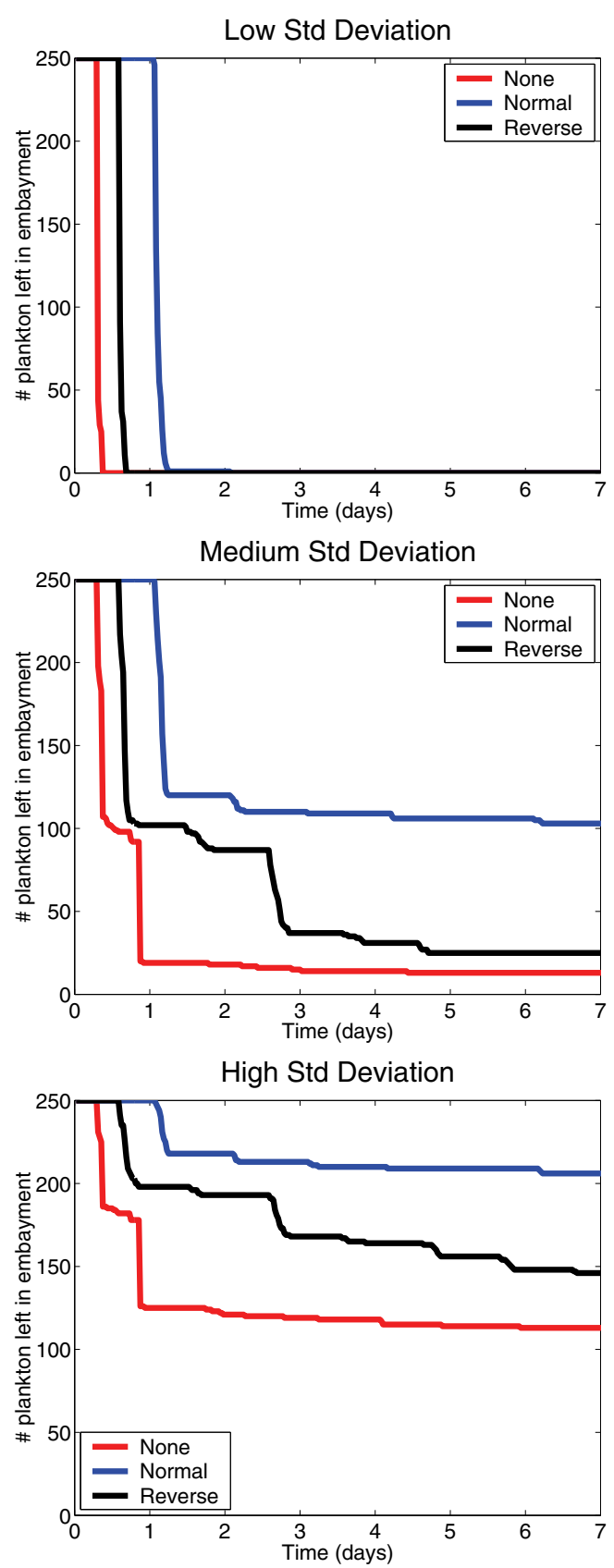

Figure 7. Number of plankton left in embayment under a range of zooplankton cloud sizes for background flow speed $0.06 \mathrm{~cm} / \mathrm{s}$, starting at midnight.

combinations of flow rate, simulation start time, migration type, and standard deviation of the zooplankton cloud, and a multiple regression analysis was performed. Standard deviation ranged in value from 0.25 to 0.75 , with consecutive values differing by 0.05 , and 18 values of flow rate were used, ranging from $0.018 \mathrm{~m}^{3} / \mathrm{s}$ to $2.466 \mathrm{~m}^{3} / \mathrm{s}$. Standard deviation and flow rate 
Table 1

Percentages of variance in biological residence time explained by the four possibly key parameters determining biological residence time. "Flow/migration type" denotes the two-way interaction between flow rate and migration type, while "Flow/migration type/standard deviation" denotes the three-way interaction between flow rate, migration type, and the zooplankton cloud size standard deviation. The proportion of total variation in biological residence time explained by the independent variables, or $R^{2}$, is 0.94 .

\begin{tabular}{|l|c|}
\hline Parameter & Percentage of variance explained \\
\hline Start time & $0.07 \%$ \\
Migration type & $6 \%$ \\
Standard deviation & $11 \%$ \\
Flow rate & $31 \%$ \\
Flow/migration type & $20 \%$ \\
Flow/migration type/standard deviation & $26 \%$ \\
\hline
\end{tabular}

were considered to be continuous variables, while start time and migration type were treated as categorical variables. As a linear model did not provide an adequate fit to the data, a generalized additive model was used. Generalized additive models are similar to generalized linear models except that smooth functions of the covariates may be used, along with the usual linear model terms, and the mean of the dependent variable is assumed to depend on an additive predictor through a nonlinear link function. In this case, spline smooths and an identity link function were utilized. Different forms and combinations of explanatory variables were tried (using the gam function in the mgcv library [49] in R [41]) until a model was found that accounted for an adequate amount of the overall variance in biological residence time and that was stable regardless of additions or removals of terms accounting for small amounts of variance. The results are shown in Table 1.

From Table 1, flow rate by itself accounts for almost a third of the variance in biological residence time, while the initial size of the zooplankton cloud (which also affects zooplankton preferred heights and depths) has the the next largest effect. Start time accounts for virtually none of the variance, as expected. The independent contribution of migration type to biological residence time is relatively small; however, interactions of migration type with other parameters are significant, with the three-way interaction of flow rate, standard deviation of zooplankton cloud, and migration type accounting for about a quarter of the variance, and the interaction between flow rate and migration type alone accounting for about $20 \%$.

\section{Analytic results.}

4.1. Single zooplankter. To test the analytic approximation against the computational results, numerical experiments were first run in MATLAB for a single zooplankter whose migration path in the vertical direction extended between the mean of the zooplankton cloud at the top and at the bottom of the water column, for seven days for all combinations of flow speed, migration type, and initial zooplankton cloud standard deviation. The first plot in Figure 8 shows computational versus analytical biological residence time results on the same set of axes. Most of the results that do not fall close to the $45^{\circ}$ line are residence times from initially large zooplankton clouds. The results to the left of the line correspond to analytic results in which all of the zooplankton wash out of the embayment, while the computational model retains some zooplankton due to the shearing effect mentioned previously. The results

Copyright (c) by SIAM. Unauthorized reproduction of this article is prohibited. 

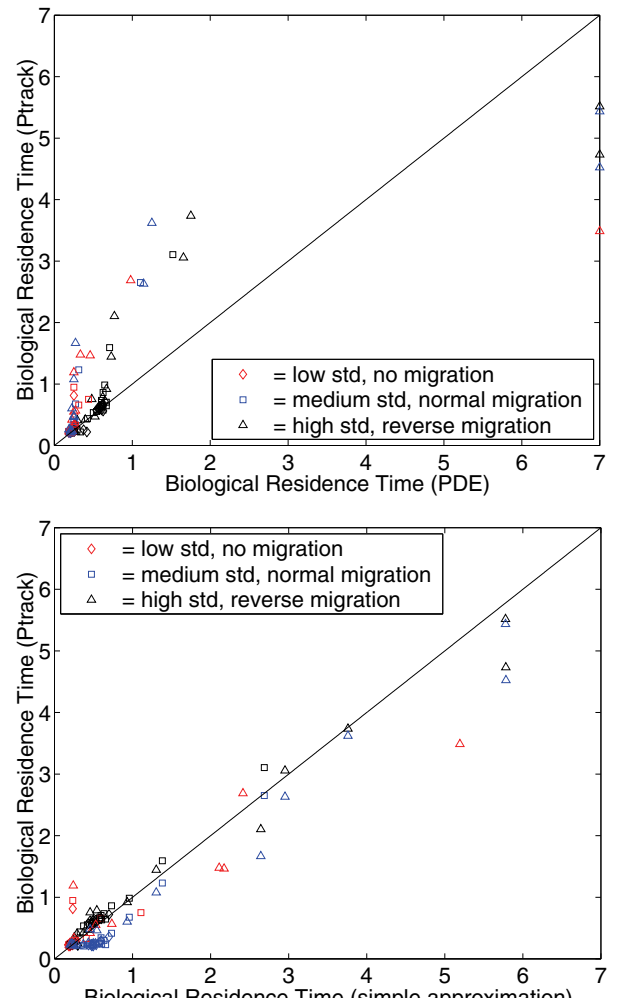

Biological Residence Time (simple approximation)

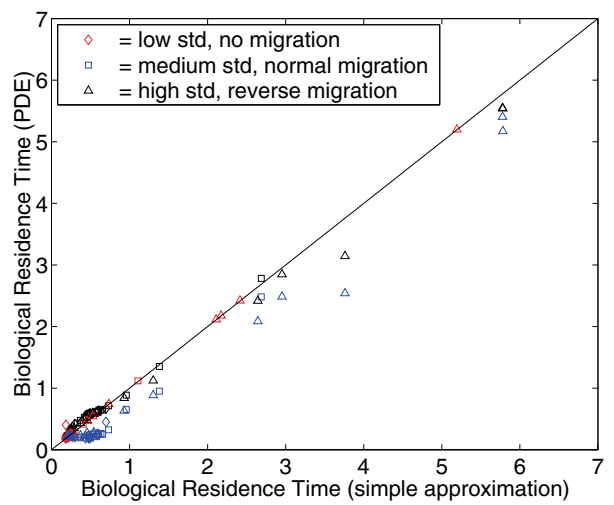

Figure 8. Top: plot of "naive" analytical biological residence time results using one zooplankter versus biological residence time results calculated using PTRACK. Middle: plot of analytical biological residence time results using Gaussian quadrature of degree 7 assuming a normal distribution versus biological residence time results calculated using PTRACK. Bottom: plot of approximate biological residence time results versus analytical biological residence time results from the PDE, both using Gaussian quadrature of degree 7 assuming a normal distribution. Color denotes migration type, while shape denotes size of initial zooplankton cloud standard deviation: red $=$ no migration, blue $=$ normal migration, black $=$ reverse migration $;$ diamond $=$ low standard deviation, square $=$ medium standard deviation, triangle $=$ high standard deviation .

to the right of the line represent scenarios in which the limited simulation time is to blame for the discrepancy.

Copyright ( by SIAM. Unauthorized reproduction of this article is prohibited. 
For the smallest zooplankton cloud, the analytical and computational results tend to be very close. For the computational model in the medium variance case at lower speeds, the more spread out zooplankton cloud now contains members low enough in the water column to experience a slower downstream velocity or even the upstream part of the exchange flow. As a result, the lowest zooplankton in the initial cloud may thus be in a position to be retained in the embayment. However, the analytical model follows a zooplankter located at the mean in the vertical of the zooplankton cloud, which cannot benefit from the velocities further down in the water column. The disadvantage of this simplification in the analytical model is seen in the large differences for the first several flow speeds between the analytical and computational results. The results for the largest zooplankton clouds demonstrate an even more pronounced effect of flow speed on residence time; lower computational than analytical results of seven days' residence time are a function of increased shearing and the limited duration of the simulations.

4.2. Zooplankton cloud. In order to more directly compare results from the analytic approximation to the computational results, we studied the movement of a cloud of zooplankton, using Gaussian quadrature to approximate the integrated movement of the cloud members (2.11). We used seven nodes chosen assuming a normal distribution of initial position and again ran numerical experiments in MATLAB for seven days for all combinations of flow speed, migration type, and initial zooplankton cloud size. The second plot in Figure 8 shows biological residence times computed using this analytical method versus those from PTRACK. While these analytical results sometimes overshoot and sometimes undershoot the true results, they are much closer in general to the computational results than were the results when following only one zooplankter. The analytical results for nonmigrating zooplankton are still not as close to the computational results for low flows as would be desirable, perhaps because these zooplankton stay at their initial starting heights (and therefore horizontal velocities) for the entire simulation and are therefore more sensitive to exactly which vertical locations are chosen as integration nodes. Because they do not migrate up and down in the water column, they are unable to take advantage of the averaging effects due to sampling a range of horizontal velocities in the water column.

4.3. Simple analytic model. Numerical experiments using the simple approximation to biological residence time, distance to the downstream boundary divided by mean horizontal zooplankton velocity, were performed for all three zooplankton cloud sizes using Gaussian quadrature of degree 7, 14, and 30. As we are assuming equal day and night lengths, this approximation gives equal values of biological residence time for normal and reverse migration. All three quadrature values showed patterns similar to the analytical results, with reverse/normal migrators usually doing significantly better than the nonmigrators, and lower flow speeds allowing increased residence time as the zooplankton cloud size increases. The approximate results again agree most closely with the computational results for the higher flow speeds and lower zooplankton cloud standard deviations. In addition, as the number of Gaussian nodes used increases, the results are closer to the computational results, although the improvement when using 30 versus 14 nodes is not significant. The third plot in Figure 8 shows approximate versus analytical results using seven Gaussian quadrature nodes, showing that the two methods give similar results, with the approximate method giving the same or a

Copyright (c) by SIAM. Unauthorized reproduction of this article is prohibited. 
higher value for biological residence time, as expected.

The previous results using Gaussian quadrature have used $z(t)$ functions of the same amplitude and simply shifted them up or down in the water column, depending on the location of the Gaussian node. To insure that this practice did not bias our results, we performed one set of approximate numerical experiments using five Gaussian quadrature nodes in which all combinations of nodes were utilized for the top and bottom positions of the $z$ function. These computations were much more time-consuming than the previous analytical or approximate computations and did not result in improved estimates of biological residence time.

5. Discussion. Small zooplanktonic organisms are often subjected to downstream drift in streams, rivers, and estuaries, yet some manage to avoid washout - the "drift paradox." In certain situations, primarily unidirectional downstream flow can be overridden by other factors which work to retain zooplankton. For example, significant temperature differences on either side of an embayment-lake interface in the summer can result in an exchange flow between embayment and lake in which the top part of the embayment experiences downstream flow and the bottom part experiences upstream flow. We investigated this flow pattern, combined with individual behavior of the zooplankton in the form of diel vertical migration, to determine whether this physical/biological interaction could result in increased residence time of the zooplankton in the embayment.

Our simulation studies using a three-dimensional hydrodynamic model coupled with an individual-based model of zooplankton diel vertical migration demonstrate that the temperature difference between a channel and lake can create exchange flow that can significantly influence zooplankton residence time. Statistical analyses indicate that factors affecting zooplankton residence time include, in decreasing order of importance, flow speed, diameter of the zooplankton cloud, migration strategy, and start time of the simulation; these analyses were corroborated by observations of zooplankton trajectories simulated using various combinations of parameters.

As background flow speed increases, exchange flow becomes less influential, and zooplankton are not advected upstream as fast when they migrate to the channel bottom. At the higher speeds tested, washout seems inevitable. Significantly, however, low flow speed by itself is not at all effective at increasing residence time; instead, as the background flow speed decreases, the channel flow is increasingly controlled by the exchange flow. Normal and reverse vertical migration under low flow conditions may both promote persistence but are more effective at different start times, which might be due to the schedule of migration and the fact that during the summer, the day (when reverse migrators are at the surface) is longer than the night (when the reverse migrators are at the bottom of the water column). Nonmigrating zooplankton do not fare as well and are swept out of the embayment at essentially the speed of the plume induced by the lock-exchange.

Regardless of whether a simple (one node) analytical method, more complicated (Gaussian quadrature) analytical method, or very simple approximate method was used, the analytical models reproduced some basic results from the computational simulations. An inverse relationship between flow speed and biological residence time was seen, and reverse migrating zooplankton remained in the embayment longer than normally migrating zooplankton over the range of flow speeds studied, with nonmigrating zooplankton always leaving the embayment first. When using a zooplankton cloud relatively small in diameter, the other parameters made

Copyright (c) by SIAM. Unauthorized reproduction of this article is prohibited. 
very little difference, and the PDE and simple approximation methods gave results very close to the computational results, even using just one simulation per parameter combination in the case of the PDE. For zooplankton clouds larger in diameter, using Gaussian quadrature made an appreciable difference in biological residence time approximations for lower flow speeds. If exact results are not necessary, the analytical method provides a relatively quick, easy, and computationally inexpensive way to estimate biological residence times.

Our computational model was necessarily a simplification of a complex, three-dimensional embayment; in reality, factors such as boulders or other impediments to flow, increased bottom roughness resulting in greater drag, elevation changes in the embayment bottom, and complex embayment geometries may decrease the relevance and upstream influence of exchange flow. On the other hand, while we did not take zooplankton reproduction into consideration, allowing the zooplankton to reproduce would presumably have increased the number (and percentage) of zooplankton remaining in the embayment at any one time. Although further studies are needed to incorporate these complex physical and behavioral aspects of real embayment/lake ecosystems into models, our efforts should make it easier to study these types of habitats in the hopes of avoiding unwittingly changing the dynamics of the zooplankton, which are basic to the health of the embayment/lake system, or zooplanktonic life stages of other organisms which require the embayment environment to survive past that stage.

\section{REFERENCES}

[1] B. R. Anholt, Density dependence resolves the stream drift paradox, Ecology, 76 (1995), pp. 2235-2239.

[2] T. B. Benjamin, Gravity currents and related phenomena, J. Fluid Mech., 31 (1968), pp. 209-248.

[3] H. Burchard, Applied Turbulence Modelling in Marine Waters, Lecture Notes in Earth Sci. 100, Springer, Berlin, 2002.

[4] Y.-H. Chen, P.-T. Shaw, And T. G. Wolcott, Enhancing estuarine retention of planktonic larvae by tidal currents, Estuarine Coastal and Shelf Sci., 45 (1997), pp. 525-533.

[5] P. Dawidowicz, J. Pijanowska, and K. Ciechomski, Vertical migration of chaoborus larvae is induced by the presence of fish, Limnol. Oceanogr., 35 (1990), pp. 1631-1637.

[6] K. N. Dimou And E. E. AdAms, A random-walk, particle tracking model for well-mixed estuaries and coastal waters, Estuarine Coastal and Shelf Sci., 37 (1993), pp. 99-110.

[7] R. Doyle-Morin, personal communication, Cornell University, Ithaca, NY, 2006.

[8] D. W. Dunsbergen And G. S. Stelling, A 3-D Particle Model for Transport Problems in Transformed Coordinates, Tech. Report 93-7, Delft University of Technology, Department of Civil Engineering, Hydraulic and Geotechnical Engineering Division, Hydromechanics Group, Delft, Netherlands, 1993.

[9] H. B. Fischer, E. J. List, R. Koh, J. Imberger, And N. Brooks, Mixing in Inland and Coastal Waters, Academic Press, New York, 1979.

[10] G. Flierl, D. Grunbaum, S. Levin, and D. Olson, From individuals to aggregations: The interplay between behavior and physics, J. Theoret. Biol., 196 (1999), pp. 397-454.

[11] C. L. Folt And C. W. Burns, Biological drivers of zooplankton patchiness, Trends in Ecol. Evolution, 14 (1999), pp. 300-305.

[12] K. E. Havens, Zooplankton dynamics in a fresh-water estuary, Arch. Hydrobiol., 123 (1991), pp. 69-97.

[13] J. HoRpPILA, Diurnal changes in the vertical distribution of cladocerans in a biomanipulated lake, Hydrobiol., 334 (1997), pp. 215-220.

[14] J. Horppila, T. Malinen, L. Nurminen, P. Tallberg, and M. Vinni, A metalimnetic oxygen minimum indirectly contributing to the low biomass of cladocerans in Lake Hiidenversi-A diurnal study on the refuge effect, Hydrobiol., 436 (2000), pp. 81-90.

[15] S. Humphries And G. D. Ruxton, Is there really a drift paradox?, J. Anim. Ecol., 71 (2002), pp. $151-154$.

Copyright $\odot$ by SIAM. Unauthorized reproduction of this article is prohibited. 
[16] J. R. Hunter, The application of Lagrangian particle-tracking techniques to modelling of dispersion in the sea, in Numerical Modelling: Applications to Marine Systems, J. Noye, ed., Elsevier Sciences, North-Holland, Amsterdam, 1987, pp. 257-269.

[17] L. Kantha and C. Clayson, An improved mixed layer model for geophysical applications, J. Geophys. Res., 99 (1994), pp. 25235-25266.

[18] P. K. Kitanidis, Particle-tracking equations for the solution of the advection-dispersion equation with variable coefficients, Water Resources Res., 30 (1994), pp. 3225-3227.

[19] W. Lampert, U. Sommer, And J. F. Haney, Limnoecology: The Ecology of Lakes and Streams, Oxford University Press, New York, 1997.

[20] J. LAnCASTER, Geometric scaling of microhabitat patches and their efficacy as refugia during disturbance, J. Anim. Ecol., 63 (2000), pp. 442-457.

[21] J. Lancaster and A. G. Hildrew, Characterising instream flow refugia, Can. J. Fish. Aquat. Sci., 50 (1993), pp. 1663-1675.

[22] J. Lancaster And A. G. Hildrew, Flow refugia and the microdistribution of lotic macroinvertebrates, J. North Amer. Bentholog. Soc., 12 (1993), pp. 285-393.

[23] F. Lutscher, E. Pachepsky, And M. A. Lewis, The effect of dispersal patterns on stream populations, SIAM J. Appl. Math., 65 (2005), pp. 1305-1327.

[24] J. G. March, J. P. Benstead, C. M. Pringle, and F. N. Scatena, Migratory drift of larval freshwater shrimps in two tropical streams, Puerto Rico, Freshwater Biol., 40 (1998), pp. 261-273.

[25] K. Mueller, Investigations on the Organic Drift in North Swedish Streams, Tech. Report 34, Institute of Freshwater Research, Drottningholm, Sweden, 1954.

[26] K. Mueller, The colonization cycle of freshwater insects, Oecologica, 53 (1982), pp. 202-207.

[27] M. D. Ohman, B. W. Frost, and E. B. Cohen, Reverse diel vertical migration: An escape from invertebrate predators, Science (N.S.), 220 (1983), pp. 1404-1407.

[28] E. Pachepsky, F. Lutscher, R. M. Nisbet, and M. A. Lewis, Persistence, spread and the drift paradox, Theor. Pop. Biol., 67 (2005), pp. 61-73.

[29] V. B. Pasour, Computational and Analytical Perspectives on the Drift Paradox Problem in a Freshwater Embayment, Ph.D. dissertation, Center for Applied Mathematics, Cornell University, Ithaca, NY, 2007.

[30] W. Reckendorfer, H. Keckeis, G. Winkler, And F. Schiemer, Zooplankton abundance in the river Danube, Austria: The significance of inshore retention, Freshwater Biol., 41 (1999), pp. 583-591.

[31] L. L. Rempel, J. S. Richardson, and M. C. Healey, Flow refugia for benthic macroinvertebrates during flooding of a large river, J. North Amer. Bentholog. Soc., 18 (1999), pp. 24-48.

[32] C. S. Reynolds, P. A. Carling, and K. Beven, Flow in river channel: New insights into hydraulic retention, Arch. Hydrobiol., 121 (1991), pp. 171-179.

[33] A. L. Robertson, J. Lancaster, And A. G. Hildrew, Stream hydraulics and the distribution of microcrustacea: A role for refugia?, Freshwater Biol., 33 (1995), pp. 469-484.

[34] F. J. Rueda, A Three-Dimensional Hydrodynamic and Transport Model for Lake Environments, Ph.D. thesis, University of California, Davis, Davis, CA, 2001.

[35] F. J. Rueda And E. A. Cowen, Residence time of a freshwater embayment connected to a large lake, Limnol. Oceanogr., 50 (2005), pp. 1638-1653.

[36] J. Smagorinsky, S. Manabe, And J. L. Holloway, Numerical results from a nine-point general circulation model of the atmosphere, Monthly Weather Rev., 93 (1965), pp. 727-768.

[37] P. E. Sмiтh, A Three-Dimensional, Finite-Difference Model for Estuarine Circulation, Ph.D. thesis, Department of Civil and Environmental Engineering, University of California, Davis, Davis, CA, 1997.

[38] D. C. Speirs And W. S. C. Gurney, Population persistence in rivers and estuaries, Ecology, 82 (2001), pp. 1219-1237.

[39] J. W. Stijnen, A. W. Heemink, And H. X. Lin, An efficient 3D particle transport model for use in stratified flow, Int. J. Numer. Methods Fluids, 51 (2006), pp. 331-350.

[40] P. G. Strutton, Phytoplankton patchiness: Quantifying the biological contribution using fast repetition rate fluorometry, J. Plankton Res., 19 (1997), pp. 1265-1274.

[41] R. D. C. Team, R: A Language and Environment for Statistical Computing, Technical report, R Foundation for Statistical Computing, Vienna, Austria, 2006.

Copyright (C) by SIAM. Unauthorized reproduction of this article is prohibited. 
[42] A. F. B. Tompson And L. W. Gelhar, Numerical simulation of solute transport in three-dimensional, randomly heterogeneous porous media, Water Resources Res., 26 (1990), pp. 2541-2562.

[43] I. Valiela, Marine Ecological Processes, Springer, New York, 1995.

[44] J. C. Warner, C. R. Sherwood, H. G. Arango, and R. P. Signell, Performance of four turbulence closure models implemented using a generic length scale method, Ocean Modelling, 8 (2005), pp. 81-113.

[45] R. Waters, The drift of stream insects, Ann. Rev. Entomol., 17 (1972), pp. 253-272.

[46] L. J. Weider And H. B. Sтісн, Spatial and temporal heterogeneity of Daphnia in Lake Constance; Intraand interspecific comparisons, Limnol. Oceanogr., 37 (1992), pp. 1327-1334.

[47] J. H. Winterbottom, S. E. Orton, And A. G. Hildrew, Field experiments on the mobility of benthic invertebrates in a southern English stream, Freshwater Biol., 38 (1997), pp. 37-47.

[48] J. H. Winterbottom, S. E. Orton, A. G. Hildrew, and J. Lancaster, Field experiments on flow refugia in streams, Freshwater Biol., 37 (1997), pp. 569-580.

[49] S. N. Wood, Generalized Additive Models: An Introduction with R, Chapman and Hall (London)/CRC Press (Boca Raton, FL), 1979.

[50] H. Yamazaki, D. L. Mackas, And K. L. Denman, Coupling small-scale physical processes with biology, in The Sea, Vol. 12, A. R. Robinson, J. J. McCarthy, and B. J. Rothschild, eds., John Wiley and Sons, New York, 2002, pp. 51-112.

Copyright ( $\odot$ by SIAM. Unauthorized reproduction of this article is prohibited. 